\title{
The role of expectancy in comparative judgments
}

\author{
EDWARD J. SHOBEN, KEVIN M. SAILOR, and MAN-YING WANG \\ University of Illinois, Champaign, Illinois
}

\begin{abstract}
Researchers interested in the processing of relational information have sought a satisfactory explanation for the congruity effect in linear orders. It is relatively easy to select either the greater of two objects that are high on a dimension or the lesser of two objects that are low on a dimension, but it is relatively difficult to determine the greater of two objects that are low in magnitude or the lesser of two objects that are high in magnitude. One explanation of the congruity effect is the expectancy hypothesis that claims that the choice of the comparative primes objects of particular magnitudes. We present two experiments that demonstrate that a congruity effect of equivalent magnitude is obtained when the comparative is presented after the stimulus pair. Moreover, this equivalence cannot be attributed to the salience of the dimensions we employed, because this equivalence held for stimuli that were classified as salient and for those classified as nonsalient. These findings are interpreted in the context of some current explanations of the congruity effect.
\end{abstract}

There has been considerable debate in recent years over how people perform comparative judgments. Some (e.g., Banks, 1977) have argued that people determine the larger of mouse and elephant by a comparison of discrete, linguistic codes. Others (e.g., Paivio, 1978) have argued that these comparisons are performed in a visual format, and have used such terms as "internal psychophysics" (Moyer \& Landauer, 1973) to indicate that the memorial comparison behaves very much like the actual perceptual comparison. More explicitly, the same operations occur both when one is presented with the physical objects mouse and elephant and when one is presented with the words mouse and elephant.

One robust effect that has been observed with memorial comparisons is the congruity effect. In general, decisions are easier when the form of the question matches the magnitude of the objects. For example, it is easier to determine the smaller of the pair mouse-rat than to determine the larger of mouse-rat. Conversely, it is easier to select the larger of rhino-elephant than to select the smaller of rhino-elephant.

This congruity effect is important theoretically because it is at least superficially at variance with analogical models that claim that such comparisons are processed in the visual system. If the difficulty of the judgment depends only on the difficulty of the visual comparison, then why should the form of the question make any difference? Supporters of propositional accounts (e.g., Banks, 1977) have argued that the congruity effect is the most difficult finding for these models to handle.

This research was supported in part by NSF Grants BNS 82-17674 and BNS 86-08214 to the first author. We are grateful to Marc Marschark for his comments on an earlier draft of this manuscript, and we are particularly grateful to him for providing us with the items used in his earlier study. Requests for reprints should be sent to Edward J. Shoben, Department of Psychology, University of Illinois, 603 East Daniel St., Champaign, IL 61820.
Marschark and Paivio (1979) offered one promising explanation for the congruity effect that was consistent with a visual explanation. They proposed an expectancy hypothesis that posited that the form of the question led people to expect objects of particular magnitudes. In terms of our example, when people are asked to decide which is larger, they tend to expect (in the experimental context) large animals (rhino and elephant) and not small ones (mouse and rat). The reverse is true when subjects are asked to select the smaller item of the pair. Thus, this model attributes congruity effects to easier retrieval of congruent items and more difficult retrieval of incongruent items.

Holyoak and Mah (1981) provided evidence that challenged the viability of this explanation of the congruity effect (see also Banks, White, Sturgill, \& Mermelstein, 1983). Holyoak and Mah reasoned that if the expectancy hypothesis is correct, then there should be no congruity effect when the question is presented after the objects to be compared. For example, if one is presented with the pair rhino-elephant, then, according to Holyoak and Mah, there is no expectancy created, and it should be just as easy to determine the smaller of this pair as to determine the larger of the two items. They took this reasoning one step further and attempted to rule out one additional modification of the expectancy hypothesis. If only the comparatives larger and smaller were used in the experiment, then subjects might be tempted to guess which one might appear; in particular, subjects who were given the pair rhino-elephant might expect the comparative larger. Accordingly, Holyoak and Mah used eight comparatives: larger, smaller, fiercer, meeker, slower, faster, smarter, and dumber. By using such a large number of comparatives, they felt that it would be very unprofitable for subjects to try to guess the comparative.

Holyoak and Mah (1981) then performed an experiment in which they presented subjects with pairs of animals (for which they previously had collected extensive ratings) and 
one of the eight comparatives. The critical manipulation was whether the comparative preceded or followed the test pair. They examined the magnitude of the congruity effect under both conditions. Contrary to the predictions of the expectancy hypothesis, there was a robust congruity effect even when the comparative followed the test stimuli. Moreover, there was not even a hint that the magnitude of the congruity effect changed as a function of presentation order. Consequently, Holyoak and Mah concluded that the expectancy hypothesis was not a viable account of the congruity effect in symbolic comparisons.

Marschark (1983) challenged this conclusion. More specifically, he argued that the data of Holyoak and Mah (1981) are suspect because of an artifact of item selection. In particular, Marschark argued that they failed to consider the variable of attribute salience. Marschark held that some comparatives are particularly salient for individual animals. He argued, for example, that the comparative larger was salient for both items in the pair rhino-elephant. Thus, Holyoak and Mah might not have precluded a guessing strategy in the condition in which the comparative followed the stimulus pair. In support of this artifactual account, Marschark obtained ratings in which subjects determined which of the eight comparatives used by Holyoak and Mah was the most strongly associated with a particular animal. Marschark then generated two set of stimulus items. In the salient list, the stimuli were pairs for which their comparative was highly salient, such as lion-eagle (fierce) and canary-flea (small). In the nonsalient list, the stimuli were pairs for which their comparative was not salient, such as racoon-badger (fierce) and tarantula-weasel (small). These two lists were randomized and presented to subjects with the comparative last. For items in the salient list, the results mirrored those obtained by Holyoak and Mah. There was a robust congruity effect such that the decision was easier when the comparative was congruent than when the comparative was incongruent. For the nonsalient pairs, the results were very different. Here, the magnitude of the congruity effect was near zero. There was a slight, and unreliable, tendency for the unmarked comparative to be easier than the marked comparative. Thus, according to Marschark, the expectancy hypothesis remains a viable account of the congruity effect. The only modification is that salience needs to be taken into account.

Although little noticed, we felt that this result was important for a number of reasons. First, it suggests that a new variable, salience, may play an important role in comparative judgments. Second, these results suggest that the congruity effect may not be as ubiquitous as previously believed. Third, and most important, it implies that one of the principal reasons for preferring a propositional account (its ease in accounting for the congruity effect) may not be justified.

Unfortunately, there are some factors that cast some doubt on the replicability of Marschark's (1983) findings. It appears that the items in the nonsalient group were less extreme in magnitude than the items in the salient group. ${ }^{1}$ For example, for "large" pairs, the items in the nonsalient group were not as large as the corresponding items in the salient group. As more extreme items (on the magnitude scale) lead to larger congruity effects, we were concerned that Marschark might have failed to find a congruity effect because the items in the nonsalient condition were not of sufficiently extreme magnitude. A second, and less serious, problem is that Marschark repeated some items in his original study. We wondered if this factor might have contributed to his failure to observe a congruity effect.

In addition to correcting what we viewed as shortcomings in this earlier study, we also wanted to investigate the effects of stimulus order on the congruity effect. More explicitly, we wondered if the effect would be attenuated when the comparative followed the stimulus pair. Marschark (1983) did not investigate this question explicitly, because he restricted his attention to conditions in which the comparative followed the stimulus pair and did not examine conditions in which the comparative preceded the stimulus pair. Nevertheless, the interaction of the magnitude of the congruity effect with pair question order is a clear prediction of the expectancy hypothesis, particularly when many comparatives are employed and guessing is singularly unprofitable for the subject.

We also were interested in the effects of salience. If, as Marschark (1983) found, this variable interacts with the congruity effect, then it seems worthy of further investigation. Is there a main effect of this variable such that salient pairs are compared more readily than are nonsalient pairs for a particular dimension? If it appears that salience is an important variable, then it would certainly be worthwhile to go on and determine whether salience interacts with other factors that are known to affect comparative judgments, such as the symbolic distance between the items in the pair.

\section{EXPERIMENT 1}

In Experiment 1, we sought to determine if people can distinguish the greater (or lesser) of two objects in magnitude more readily if the comparative is salient than if it is nonsalient. To provide additional constraint on the interaction that Marschark (1983) observed between this salience variable and the congruity effect, we presented our stimuli with the comparative after the pairs of animal names (as did Marschark) and also with the comparative before the pairs.

\section{Method}

The subjects decided which of two animal names was greater or lesser along a particular dimension. The experimental dimensions were size and ferocity, and two additional dimensions, speed and intelligence, were used as fillers. These dimensions were the same as those used by Holyoak and Mah (1981) and Marschark (1983). The animal names were also selected from those used in both earlier studies. Normative values for the animals were taken from Holyoak and Mah's study. There were two groups of subjects. The subjects who received the comparative first saw the comparative, followed $2 \mathrm{sec}$ later by the pair of animal names. The subjects in the com- 
parative last condition saw the pair of animal names for $2 \mathrm{sec}$, followed by the comparative.

Materials. Sixteen pairs of animal names were constructed for each of the two experimental dimensions, size and ferocity. Of these 16,8 were formed such that the pairs were low in magnitude, and 8 were high in magnitude on that particular dimension. For each of the groups of 8 pairs, 4 were high salience (Marschark, 1983) and 4 were low salience. In Marschark's norms, the values of salience range from 0 to 56 , corresponding to the number of subjects who listed that adjective as their first association for a particular animal. The definition of salience varied as a function of the dimension. In the norms collected by Marschark, the attributes large and small were more strongly associated with the animal names than any of the other attributes. Accordingly, a salient "small" pair contained two animals that often had small as their most salient attribute. A nonsalient pair contained only one such item. Thus, for example, canary-owl was a nonsalient pair because smart is most strongly associated with owl. For both items of the salient pair mole-worm, small was the most strongly associated attribute. In contrast, for "meek" items, often only one item in a salient pair would be strongly associated with the adjective meek, as in the pair sheep-zebra; in nonsalient pairs, such as ostrich-flea, neither item was most strongly associated with meek. Complete details for the experimental items are given in Table 1. To avoid the confound between salience and magnitude that might have influenced Marschark's results, we attempted to control for the mean magnitude separately for "large," "small," "fierce," and "meek" stimuli. Given the obvious fact that items that are extreme on a dimension are more likely to be salient on that dimension, such an equivalence was not easy to achieve. In order to do so, we relaxed the implicit requirement that all items in the salient pairs be higher in salience than all items in the nonsalient pairs. Although these distributions overlapped, they clearly differed in salience. For the salient group, the mean salience rating was 22.12 , whereas it was

Table 1

Experimental Pairs of Experiment 1, with Magnitude and Salience Ratings

\begin{tabular}{|c|c|c|c|c|c|}
\hline \multicolumn{3}{|c|}{ Salient } & \multicolumn{3}{|c|}{ Nonsalient } \\
\hline Pair & Magnitude & Salience & Pair & Magnitude & Salience \\
\hline \multicolumn{6}{|c|}{ Fierce Pairs } \\
\hline $\begin{array}{l}\text { alligator- } \\
\text { hippo }\end{array}$ & $\begin{array}{l}8.88 \\
6.02\end{array}$ & $\begin{array}{r}44 \\
1\end{array}$ & $\begin{array}{l}\text { rhino- } \\
\text { chimpanzee }\end{array}$ & $\begin{array}{l}8.45 \\
5.28\end{array}$ & $\begin{array}{r}12 \\
1\end{array}$ \\
\hline $\begin{array}{l}\text { tiger- } \\
\text { elephant }\end{array}$ & $\begin{array}{l}9.57 \\
6.75\end{array}$ & $\begin{array}{r}54 \\
1\end{array}$ & $\begin{array}{l}\text { polar bear- } \\
\text { dog }\end{array}$ & $\begin{array}{l}8.69 \\
5.78\end{array}$ & $\begin{array}{r}12 \\
1\end{array}$ \\
\hline $\begin{array}{l}\text { leopard- } \\
\text { fox }\end{array}$ & $\begin{array}{l}9.45 \\
6.14\end{array}$ & $\begin{array}{r}27 \\
7\end{array}$ & $\begin{array}{l}\text { bull- } \\
\text { horse }\end{array}$ & $\begin{array}{l}7.76 \\
4.85\end{array}$ & $\begin{array}{r}21 \\
0\end{array}$ \\
\hline $\begin{array}{l}\text { lion- } \\
\text { eagle }\end{array}$ & $\begin{array}{l}9.16 \\
7.13\end{array}$ & $\begin{array}{l}52 \\
16\end{array}$ & $\begin{array}{l}\text { coyote- } \\
\text { turkey }\end{array}$ & $\begin{array}{l}7.52 \\
4.20\end{array}$ & $\begin{array}{r}14 \\
0\end{array}$ \\
\hline \multicolumn{6}{|c|}{ Meek Pairs } \\
\hline $\begin{array}{l}\text { zebra- } \\
\text { sheep }\end{array}$ & $\begin{array}{l}5.06 \\
3.33\end{array}$ & $\begin{array}{l}13 \\
37\end{array}$ & $\begin{array}{l}\text { seagull- } \\
\text { goldfish }\end{array}$ & $\begin{array}{l}3.77 \\
1.35\end{array}$ & $\begin{array}{l}18 \\
10\end{array}$ \\
\hline $\begin{array}{l}\text { beaver- } \\
\text { mouse }\end{array}$ & $\begin{array}{l}5.24 \\
3.08\end{array}$ & $\begin{array}{r}3 \\
12\end{array}$ & $\begin{array}{l}\text { ostrich- } \\
\text { flea }\end{array}$ & $\begin{array}{l}4.81 \\
2.52\end{array}$ & $\begin{array}{l}5 \\
0\end{array}$ \\
\hline $\begin{array}{l}\text { ox- } \\
\text { duck }\end{array}$ & $\begin{array}{l}5.87 \\
3.46\end{array}$ & $\begin{array}{r}0 \\
15\end{array}$ & $\begin{array}{l}\text { gazelle- } \\
\text { snail }\end{array}$ & $\begin{array}{l}4.08 \\
1.29\end{array}$ & $\begin{array}{l}4 \\
2\end{array}$ \\
\hline $\begin{array}{l}\text { crab- } \\
\text { dove }\end{array}$ & $\begin{array}{l}4.39 \\
2.33\end{array}$ & $\begin{array}{r}0 \\
29\end{array}$ & $\begin{array}{l}\text { donkey- } \\
\text { rabbit }\end{array}$ & $\begin{array}{l}5.20 \\
2.79\end{array}$ & $\begin{array}{r}1 \\
10\end{array}$ \\
\hline \multicolumn{6}{|c|}{ Large Pairs } \\
\hline $\begin{array}{l}\text { moose- } \\
\text { pig }\end{array}$ & $\begin{array}{l}7.04 \\
4.58\end{array}$ & $\begin{array}{r}36 \\
5\end{array}$ & $\begin{array}{l}\text { gorilla- } \\
\text { wolf }\end{array}$ & $\begin{array}{l}6.61 \\
5.00\end{array}$ & $\begin{array}{r}22 \\
0\end{array}$ \\
\hline $\begin{array}{l}\text { buffalo- } \\
\text { bobcat }\end{array}$ & $\begin{array}{l}7.14 \\
4.63\end{array}$ & $\begin{array}{r}50 \\
1\end{array}$ & $\begin{array}{l}\text { cow- } \\
\text { seal }\end{array}$ & $\begin{array}{l}6.52 \\
5.23\end{array}$ & $\begin{array}{r}19 \\
5\end{array}$ \\
\hline $\begin{array}{l}\text { giraffe- } \\
\text { panda }\end{array}$ & $\begin{array}{l}7.70 \\
5.77\end{array}$ & $\begin{array}{l}41 \\
10\end{array}$ & $\begin{array}{l}\text { camel- } \\
\text { deer }\end{array}$ & $\begin{array}{l}6.96 \\
5.73\end{array}$ & $\begin{array}{r}15 \\
1\end{array}$ \\
\hline $\begin{array}{l}\text { walrus- } \\
\text { boar }\end{array}$ & $\begin{array}{l}6.59 \\
5.11\end{array}$ & $\begin{array}{r}30 \\
7\end{array}$ & $\begin{array}{l}\text { shark- } \\
\text { octopus }\end{array}$ & $\begin{array}{l}6.64 \\
4.66\end{array}$ & $\begin{array}{r}2 \\
12\end{array}$ \\
\hline \multicolumn{6}{|c|}{ Small Pairs } \\
\hline $\begin{array}{l}\text { lobster- } \\
\text { fly }\end{array}$ & $\begin{array}{r}2.88 \\
.79\end{array}$ & $\begin{array}{l}25 \\
41\end{array}$ & $\begin{array}{l}\text { chicken- } \\
\text { sparrow }\end{array}$ & $\begin{array}{l}3.51 \\
2.52\end{array}$ & $\begin{array}{r}8 \\
31\end{array}$ \\
\hline $\begin{array}{l}\text { penguin- } \\
\text { toad }\end{array}$ & $\begin{array}{l}4.01 \\
2.18\end{array}$ & $\begin{array}{r}9 \\
33\end{array}$ & $\begin{array}{l}\text { goat- } \\
\text { chipmunk }\end{array}$ & $\begin{array}{l}4.77 \\
2.62\end{array}$ & $\begin{array}{r}1 \\
32\end{array}$ \\
\hline $\begin{array}{l}\text { raccoon- } \\
\text { hummingbird }\end{array}$ & $\begin{array}{l}3.70 \\
2.03\end{array}$ & $\begin{array}{l}18 \\
34\end{array}$ & $\begin{array}{l}\text { otter- } \\
\text { frog }\end{array}$ & $\begin{array}{l}4.07 \\
2.28\end{array}$ & $\begin{array}{l}16 \\
35\end{array}$ \\
\hline $\begin{array}{l}\text { mole- } \\
\text { worm }\end{array}$ & $\begin{array}{l}3.03 \\
1.31 \\
\end{array}$ & $\begin{array}{l}28 \\
29 \\
\end{array}$ & $\begin{array}{l}\text { owl- } \\
\text { canary }\end{array}$ & $\begin{array}{l}3.45 \\
2.33\end{array}$ & $\begin{array}{r}4 \\
36 \\
\end{array}$ \\
\hline
\end{tabular}

Note-Magnitude ratings taken from Holyoak and Mah (1981). Salience ratings taken from Marschark (1983). 
only 10.94 in the nonsalient group. Thus, despite the fact that these distributions of salience ratings overlapped, there is no question that they differed appreciably on this variable.

By varying salience in this fashion, we were able to match the conditions in magnitude quite precisely. Magnitude, in the Holyoak and Mah (1981) norms, ranged from 0 to 10. For the "large" items, the mean magnitude was 6.07 ( $S D=1.14)$ for the salient pairs and $5.92(S D=.82)$ for the nonsalient pairs. For the small items, the mean magnitude was $2.49(S D=1.05)$ for the salient pairs and $3.18(S D=.86)$ for the nonsalient pairs. For the "fierce" items, the corresponding means were $7.85(S D=1.39)$ for the salient pairs and $6.56(S D=1.63)$ for the nonsalient items. Finally, for the "meek" items, the mean magnitude was $4.10(S D=1.15)$ for the salient items and $3.23(S D=1.39)$ for the nonsalient items. All ratings were taken from the Holyoak and Mah norms for size and ferocity. Over all four comparisons, the salient group was neither more nor less extreme in magnitude than the nonsalient group.

We also felt that it was important not to confound the salience manipulation with symbolic distance. More specifically, pairs of items that differ greatly in magnitude (high symbolic distance) are more readily discriminated than items that are close in magnitude: therefore, it was important to control for symbolic distance. ${ }^{2}$ For the pairs based on size, the mean difference was 1.96 units ( $S D$ $=.35$ ) for the salient pairs and 1.54 units $(S D=.39)$ for the nonsalient pairs. For the pairs based on ferocity, the difference was similar in magnitude but reversed in direction: 2.39 for the salient pairs $(S D=.44)$ and 2.78 for the nonsalient pairs $(S D=.34$ ) Overall, it appears that salient and nonsalient pairs were equated for symbolic distance.

Design. The experimental items used in Experiment 1 varied in terms of the dimension (ferocity or size), the comparative (greater or lesser), the magnitude of the animal names (greater or lesser), and the salience of the items (salient or nonsalient). This breakdown is reflected in the items displayed in Table 1. In addition to these within-subject factors, whether the animal names preceded the comparative or whether the comparative preceded the animal names was a between-subjects factor.

Each of the 32 experimental pairs was presented four times in the experiment, twice with the "greater" comparative and twice with the "lesser" comparative. The side on which the correct answer occurred was counterbalanced with the form of the question. In addition to these 128 experimental trials, the subjects saw 32 filler trials, drawn from the dimensions of speed and intelligence. Each filler trial was presented once. The ordering of the stimuli was determined randomly for each subject. Groups of subjects were assigned randomly to either the comparative first or the comparative last condition.

Procedure. The subjects were seated in semiprivate cubicles in front of a Mime 340 terminal. Up to 4 subjects were run simultaneously. Each trial began with a ready signal (the word "ready"), which remained on the screen until the subject pressed the space bar. In the comparative first condition, pressing the space bar brought on the comparative, followed $1.5 \mathrm{sec}$ later by the test pair, displayed side by side. The subject responded by pressing the 9 key on the console if the correct answer was on the right and the 5 key if the correct answer was on the left. In the comparative last condition, the test pair appeared for $2 \mathrm{sec}$, followed by the comparative. Reaction time (RT) was measured from the onset of the test pair in the comparative first condition, and from the onset of the comparative in the comparative last condition. If the subject made an erroneous response, the message "Wrong answer" delayed the presentation of the ready signal and the onset of the next trial.

The subjects were instructed to respond as quickly and as accurately as possible. They performed 20 practice trials before the experiment, with materials not among the test stimuli but that required judgments about the four dimensions that were to be used in the experiment. They were given a 2-min break halfway through the experimental trials.

Subjects. The subjects were 64 University of Illinois undergraduates who were participating in partial fulfillment of a course requirement. All were right-handed and native speakers of English.

\section{Results}

The overall error rate in Experiment 1 was $6.7 \%$ and errors correlated positively with RTs $(r=.59)$, which were the data of primary interest. RTs longer than $3.5 S D$ s above the mean (for each subject) were excluded from the RT analysis and treated as errors.

The most important results of Experiment 1 concern the condition in which the test pair preceded the comparative. Using this comparative last procedure, Marschark (1983) found a congruity effect only for salient pairs. He interpreted this finding as support for the expectancy hypothesis explanation of the congruity effect. The present results are in sharp contrast to Marschark's findings. In the comparative last condition, we found a strong congruity effect of $53 \mathrm{msec}$ for the salient stimuli and $44 \mathrm{msec}$ for the nonsalient stimuli. ${ }^{3}$ Overall, this congruity effect was highly reliable $[F(1,31)=59.22, M S e=20,359$, $p<.01]$. Most importantly, there was no hint of an interaction of the congruity effect with salience $[F(1,31)$ $<$ 1]. The results are presented in Table 2.

Although the statistical analysis indicates that these effects were quite robust, it should be noted that the magnitude of the congruity effect for the salient items was much smaller than that obtained by Marschark (1983). There are several possible explanations for this difference. First, his overall RTs were much longer than ours, perhaps because of differences in apparatus, or because his stimulus items were exposed for only $1 \mathrm{sec}$. Second, his salient items were more extreme in magnitude than ours. In all four possible cases, the magnitudes of Marschark's items were more extreme than those of the items we used in Experiment 1. Thus, the fact that Marschark's congruity effect was larger than ours in this condition is not terribly surprising.

Interestingly, the overall effect of salience was not significant in Experiment $1[F(1,31)<1]$; salient pairs were discriminated only $7 \mathrm{msec}$ faster than nonsalient ones. This variable, however, interacted reliably with two other factors in this analysis. First, there was a significant interaction with question type $[F(1,31)=8.02, M S e=$ $17,906, p<.01$ ], such that "greater" comparatives were $40 \mathrm{msec}$ faster for salient pairs, but "lesser" compara-

Table 2

Reaction Times (Error Rates in Parentheses) for the Comparative Last Condition as a Function of Salience, Magnitude, and Question Type

\begin{tabular}{|c|c|c|c|c|}
\hline \multirow{3}{*}{$\begin{array}{c}\text { Question } \\
\text { Type }\end{array}$} & \multicolumn{4}{|c|}{ Magnitude } \\
\hline & \multicolumn{2}{|c|}{ Salient } & \multicolumn{2}{|c|}{ Nonsalient } \\
\hline & Low & High & Low & High \\
\hline Greater & $1105(.05)$ & $1064(.07)$ & $1164(.06)$ & $1086(.05)$ \\
\hline Lesser & $1105(.06)$ & $1275(.08)$ & $1115(.07)$ & $1213(.07)$ \\
\hline Difference & 0 & $-2 I 1$ & 49 & -127 \\
\hline
\end{tabular}


tives were 26 msec slower for salient pairs. A similar interaction occurred with dimension. For questions about ferocity, salient pairs were $47 \mathrm{msec}$ faster, but for questions about size, salient pairs were $33 \mathrm{msec}$ slower $[F(1,31)=5.86, M S e=35,587, p<.025]$. We will defer consideration of these interactions until after we have discussed the results of the comparative first condition. The only other reliable effect in the comparative last condition was a main effect of dimension, reflecting the relative ease ( $82 \mathrm{msec}$ faster) of size judgments when compared with ferocity judgments $[F(1,31)=15.10, M S e=$ $56,258, p<.01]$.

In all important respects, the results of the comparative first condition paralleled those of the comparative last condition. Most importantly, there was again a robust congruity effect that did not interact with the salience of the stimulus pair. These results are displayed in Table 3. Because the subjects read two words (the test pair) instead of one (the comparative), the RTs recorded in Table 3 are longer than those recorded in Table 2, but the pattern of results is nearly identical. For the salient pairs, the congruity effect was $68 \mathrm{msec}$, and this effect decreases only to $62 \mathrm{msec}$ for the nonsalient pairs. Again, the congruity effect was highly reliable $[F(1,31)=71.98, M S \mathrm{e}$ $=29,637, p<.01]$. Moreover, there was again no hint of an interaction with the salience of the stimuli $[F(1,31)$ $<1]$.

In contrast to the results of the comparative last condition, however, we observed a 36-msec main effect of salience $[F(1,31)=6.97, M S \mathrm{e}=23,998, p<.02]$. Also, in contrast to the comparative last condition, salience interacted with neither question type $[F(1,31)=$ $2.05, p>.10]$ nor dimension $[F(1,31)=1.85$, $p>.10]$. Although these nonsignificant interactions might seem to conflict with our earlier results, it is important to note that the direction of the effect was the same in both cases. Specifically, the facilitative effect of salience was again more for the "greater" comparative than for the "lesser" comparative, and the effect of salience was also more pronounced for questions about ferocity than for questions about size. Thus, despite the negative results in this comparative first condition, it would seem premature to dismiss as spurious the interactions of salience that we obtained in the comparative last condition.

As in the comparative last condition, the data from the comparative first condition also exhibited a main effect of dimension. Questions about size were answered

Table 3

Reaction Times (Error Rates in Parentheses) for the Comparative First Condition as a Function of Salience, Magnitude, and Question Type

\begin{tabular}{|c|c|c|c|c|}
\hline \multirow{3}{*}{$\begin{array}{c}\text { Question } \\
\text { Type }\end{array}$} & \multicolumn{4}{|c|}{ Magnitude } \\
\hline & \multicolumn{2}{|c|}{ Salient } & \multicolumn{2}{|c|}{ Nonsalient } \\
\hline & Low & High & Low & High \\
\hline $\begin{array}{l}\text { Greater } \\
\text { Lesser }\end{array}$ & $\begin{array}{l}1332(.08) \\
1231(.09)\end{array}$ & $\begin{array}{l}1322(.10) \\
1516(.11)\end{array}$ & $\begin{array}{l}1375(.08) \\
1273(.05)\end{array}$ & $\begin{array}{l}1379(.07) \\
1524(.08)\end{array}$ \\
\hline Difference & 101 & -194 & 102 & -145 \\
\hline
\end{tabular}

$42 \mathrm{msec}$ faster than were questions about ferocity. Moreover, this effect also interacted with question type such that the differences between the dimensions were tiny when the "greater" comparative was used, but quite large $(71 \mathrm{msec})$ when the "lesser" comparative was used. Also in contrast to the earlier condition, there was a large effect of magnitude in the comparative first condition. Items high in magnitude were 139 msec more difficult than were items low in magnitude $[F(1,31)=47.05, M S e=52,336$, $p<.01$ ]. This effect contrasts with a nonsignificant 37msec effect (in the same direction) in the prior condition. One artifactual explanation for this result is that our highmagnitude items were harder to retrieve. When the stimuli are presented (in the comparative last condition), this difference does not enter into the RT.

Perhaps it is useful to examine the results of the two conditions simultaneously. Proponents of the expectancy hypothesis (Marschark \& Paivio, 1979) claim that there should be marked differences between the comparative first and the comparative last condition. Marschark's (1983) results suggest that these differences should be paramount in comparisons involving nonsalient items. In fact, the order of presentation seemed to have a minimal effect on performance. Although there was a main effect of stimulus order, reflecting the more rapid decisions in the comparative last condition $[F(1,62)=9.15, M S e=$ $1,466,900, p<.01]$, there was only one interaction with this variable. As one might guess from the preceding results, stimulus order interacted with the magnitude of the stimuli; pairs that were small in magnitude were much easier than were pairs that were large in magnitude when the comparative came first, but only marginally easier when the comparative came last $[F(1,62)=13.31, M S \mathrm{e}$ $=49,612, p<.01]$. Most importantly, stimulus order did not interact with the salience of the pair $[F(1,62)=$ $2.90, p>.05]$. To summarize, the magnitude of the congruity effect was unaffected by whether the comparative preceded or followed the test stimuli. Moreover, this absence of an effect was not qualified by any interactions with salience.

When both conditions were examined jointly, the remaining interactions reflected the effects that we noted earlier. Looking first at two-way interactions, there were reliable interactions between salience and question type $[F(1,62)=9.89, M S e=13.194]$ and between salience and dimension $[F(1,62)=7.39, M S e=31,431]$ (both $p$ s $<.01$ ), reflecting the interactions we observed in the comparative last condition. Analogously, question type interacted with dimension, as it did in the comparative first condition $[F(1,62)=4.64, M S e=25,780, p<.05]$. There was also an interaction of dimension by magnitude, as there was in both the comparative first and the comparative last conditions $[F(1,62)=38.60, M S e=34,931$, $p<.01$, again reflecting the fact that smaller magnitude pairs were discriminated more readily only when the dimension was size.

There were 16 higher-order interactions, only one of which had a $p$ value of less than .10. The interaction of 
question type with salience also interacted with dimension such that the interaction of question with salience was more pronounced for size questions than for ferocity questions.

One might want to quarrel with our empirical conclusions on the grounds that our nonsalient pairs were, in fact, salient. In order to equate the items for magnitude, often one member of the nonsalient pair was, according to Marschark's (1983) norms, fairly salient (see Table 1). Although we felt that this explanation was unlikely a priori, we examined this possibility in Experiment 2.

\section{EXPERIMENT 2}

Experiment 2 examined the effects of stimulus-comparative order on stimuli that were clearly nonsalient. No item used in this study had a salience rating greater than 17 for its particular dimension.

\section{Method}

The task and dimensions used in Experiment 2 were identical to those of Experiment 1. Again, there were two groups of subjects. The subjects who received the comparative first saw the comparative, followed 2 sec later by the pair of animal names. The sub- jects in the comparative last condition saw the pair of animal names for $2 \mathrm{sec}$, followed by the comparative. In contrast to Experiment I. none of the items used in Experiment 2 was salient on the dimension for which it was tested.

Materials. Because the major purpose of Experiment 2 was to allay concern that even the presence of one slightly salient item in Experiment 1 might have affected our results, the items were selected for each dimension to be particularly low on salience. No item that appeared in judgments of ferocity had a rating greater than 17 on the Marschark norms, and no item that appeared in judgments of size had a rating greater than 16 on these norms.

As in Experiment 1, items were segregated into groups of highmagnitude pairs and low-magnitude pairs. Each pair consisted of a more extreme member and a less extreme member. This arrangement meant that pairs from both the high-magnitude group and the low-magnitude group had one member that had a higher magnitude than the other member of the pair. On the size dimension, the mean value for the more extreme member of the high-magnitude group was 6.49 and for the less extreme member of the highmagnitude group was 5.61, while the mean values for the more extreme member and less extreme member of the low-magnitude group were 3.7 and 2.75 , respectively. Thus, the differences between the more extreme and less extreme members were roughly equivalent for the two groups. On the ferocity dimension, the mean value for the more extreme member of the high-magnitude group was 9.1 and for the less extreme member was 5.66, while the mean values for the more and less extreme members of the low-magnitude

Table 4

Experimental Pairs of Experiment 2, with Magnitude and Salience Ratings

\begin{tabular}{|c|c|c|c|c|c|}
\hline Pair & Magnitude & Salience & Pair & Magnitude & Salience \\
\hline \multicolumn{6}{|c|}{ Fierce Pairs } \\
\hline $\begin{array}{l}\text { buffalo- } \\
\text { raccoon }\end{array}$ & $\begin{array}{l}6.59 \\
5.41\end{array}$ & $\begin{array}{l}2 \\
1\end{array}$ & $\begin{array}{l}\text { fox- } \\
\text { bat }\end{array}$ & $\begin{array}{l}6.14 \\
5.38\end{array}$ & $\begin{array}{l}0 \\
5\end{array}$ \\
\hline $\begin{array}{l}\text { coyote- } \\
\text { walrus }\end{array}$ & $\begin{array}{l}7.52 \\
5.89\end{array}$ & $\begin{array}{r}14 \\
1\end{array}$ & $\begin{array}{l}\text { hippo- } \\
\text { rat }\end{array}$ & $\begin{array}{l}6.02 \\
5.43\end{array}$ & $\begin{array}{l}1 \\
4\end{array}$ \\
\hline $\begin{array}{l}\text { elephant- } \\
\text { ox }\end{array}$ & $\begin{array}{l}6.75 \\
5.87\end{array}$ & $\begin{array}{r}16 \\
4\end{array}$ & $\begin{array}{l}\text { rhino- } \\
\text { moose }\end{array}$ & $\begin{array}{l}8.45 \\
5.98\end{array}$ & $\begin{array}{r}12 \\
4\end{array}$ \\
\hline \multicolumn{6}{|c|}{ Meek Pairs } \\
\hline $\begin{array}{l}\text { chipmunk- } \\
\text { canary }\end{array}$ & $\begin{array}{l}3.62 \\
2.24\end{array}$ & $\begin{array}{r}6 \\
10\end{array}$ & $\begin{array}{l}\text { toad- } \\
\text { goldfish }\end{array}$ & $\begin{array}{l}2.54 \\
1.35\end{array}$ & $\begin{array}{r}3 \\
10\end{array}$ \\
\hline $\begin{array}{l}\text { duck- } \\
\text { frog }\end{array}$ & $\begin{array}{l}3.46 \\
2.05\end{array}$ & $\begin{array}{r}15 \\
7\end{array}$ & $\begin{array}{l}\text { mouse- } \\
\text { sparrow }\end{array}$ & $\begin{array}{l}3.08 \\
2.35\end{array}$ & $\begin{array}{r}12 \\
7\end{array}$ \\
\hline $\begin{array}{l}\text { gopher- } \\
\text { flea }\end{array}$ & $\begin{array}{l}3.98 \\
2.52\end{array}$ & $\begin{array}{r}14 \\
0\end{array}$ & $\begin{array}{l}\text { penguin- } \\
\text { worm }\end{array}$ & $\begin{array}{l}3.75 \\
0.00\end{array}$ & $\begin{array}{r}17 \\
5\end{array}$ \\
\hline \multicolumn{6}{|c|}{ Large Pairs } \\
\hline $\begin{array}{l}\text { camel- } \\
\text { donkey }\end{array}$ & $\begin{array}{l}6.96 \\
5.98\end{array}$ & $\begin{array}{r}15 \\
1\end{array}$ & $\begin{array}{l}\text { cow- } \\
\text { antelope }\end{array}$ & $\begin{array}{l}6.52 \\
5.77\end{array}$ & $\begin{array}{l}19 \\
11\end{array}$ \\
\hline $\begin{array}{l}\text { horse- } \\
\text { deer }\end{array}$ & $\begin{array}{l}6.66 \\
5.73\end{array}$ & $\begin{array}{r}11 \\
1\end{array}$ & $\begin{array}{l}\text { lion- } \\
\text { alligator }\end{array}$ & $\begin{array}{l}6.10 \\
5.46\end{array}$ & $\begin{array}{l}2 \\
4\end{array}$ \\
\hline $\begin{array}{l}\text { shark- } \\
\text { dolphin }\end{array}$ & $\begin{array}{l}6.64 \\
5.74\end{array}$ & $\begin{array}{l}2 \\
1\end{array}$ & $\begin{array}{l}\text { tiger- } \\
\text { wolf }\end{array}$ & $\begin{array}{l}6.05 \\
5.00\end{array}$ & $\begin{array}{l}0 \\
0\end{array}$ \\
\hline \multicolumn{6}{|c|}{ Small Pairs } \\
\hline $\begin{array}{l}\text { eagle- } \\
\text { rabbit }\end{array}$ & $\begin{array}{l}3.89 \\
3.48\end{array}$ & $\begin{array}{l}2 \\
8\end{array}$ & $\begin{array}{l}\text { weasel- } \\
\text { snail }\end{array}$ & $\begin{array}{l}3.69 \\
1.47\end{array}$ & $\begin{array}{l}13 \\
13\end{array}$ \\
\hline $\begin{array}{l}\text { beaver- } \\
\text { squirrel }\end{array}$ & $\begin{array}{l}3.80 \\
3.16\end{array}$ & $\begin{array}{r}6 \\
14\end{array}$ & $\begin{array}{l}\text { cat- } \\
\text { dove }\end{array}$ & $\begin{array}{l}3.60 \\
2.82\end{array}$ & $\begin{array}{r}8 \\
19\end{array}$ \\
\hline $\begin{array}{l}\text { turkey- } \\
\text { chicken }\end{array}$ & $\begin{array}{l}3.79 \\
3.51\end{array}$ & $\begin{array}{l}4 \\
8\end{array}$ & $\begin{array}{l}\text { owl- } \\
\text { tarantula }\end{array}$ & $\begin{array}{l}3.45 \\
2.11\end{array}$ & $\begin{array}{r}4 \\
10\end{array}$ \\
\hline
\end{tabular}

Note-Magnitude ratings taken from Holyoak and Mah (1981). Salience ratings taken from Marschark (1983). 
group were 3.40 and 1.75 , respectively. The mean difference between each member of a pair was 1.25 for the high-magnitude group and $\mathbf{1 . 6 5}$ for the low-magnitude group.

Design. The experimental items used in Experiment 2 varied in terms of the dimension (ferocity or size), the comparative (greater or lesser), the magnitude of the animal names (greater or lesser), and the salience of the items (salient or nonsalient). This breakdown is reflected in the items displayed in Table 4. In addition to these within-subject factors, whether the animal names preceded the comparative or whether the comparative preceded the animal names was a between-subjects factor.

There were two blocks of trials. Each of the 24 experimental pairs was presented four times in a block, twice with the "greater" comparative and twice with the "lesser" comparative. The side on which the correct answer occurred was counterbalanced with the form of the question. In addition to these 96 experimental trials, the subjects also saw 48 filler trials, drawn from the dimensions of speed and intelligence. Within a block, each filler trial was presented once with the "greater" comparative and once with the "lesser" comparative. The order of presentation was randomized, with the additional constraint that no pair could appear twice within the space of three trials. Groups of subjects were assigned randomly to either the comparative first or the comparative last condition.

Procedure. The subjects were seated in semiprivate cubicles in front of a Mime 340 terminal. Up to 4 subjects were run simultaneously. Each trial began with a ready signal (the word "ready"), which remained on the screen until the subject pressed the space bar. In the comparative first condition, pressing the space bar brought on the comparative. It was followed $1.5 \mathrm{sec}$ later by the test pair of words, displayed side by side. The subjects responded by pressing the $9 \mathrm{key}$ on the console if the correct answer was on the right and the $5 \mathrm{key}$ if the correct answer was on the left. In the comparative last condition, the order was reversed; the test pair appeared for $2 \mathrm{sec}$, followed by the comparative. RT was measured from the onset of the test pair in the comparative first condition, and from the onset of the comparative in the comparative last condition. If the subject made an erroneous response, the message "Wrong answer" delayed the presentation of the ready signal and the onset of the next trial.

The subjects were instructed to respond as quickly and as accurately as possible. They performed 20 practice trials before the experiment, with materials not among the test stimuli but that required judgments about the four dimensions that were to be used in the experiment. They were given a 2 -min break halfway through the experimental trials.

Subjects. The subjects were 53 University of Illinois undergraduates who participated in partial fulfillment of a course requirement. None had participated in Experiment 1. Six subjects were excluded from further analyses because they made more than 25 errors during the course of the experiment.

\section{Results}

The overall error rate was $8.7 \%$. As in Experiment 1, errors correlated positively with the RTs $(r=.72)$, and RTs in excess of $3 S D$ s above the mean were excluded from the analysis.

Even with stimuli that were extremely nonsalient, we still obtained our two principal findings. First, there was a reliable congruity effect for these stimuli, even when the comparative followed the stimulus pair. In addition, the magnitude of the congruity effect was virtually identical to that obtained when the comparative preceded the stimulus pair.

The results are shown in Table 5. In the comparative last condition, there was a $36-\mathrm{msec}$ congruity effect of
Table 5

Reaction Times (Error Rates in Parentheses) as a Function of Order (Comparative First or Comparative Last) on the Magnitude of the Congruity Effect in Experiment 2

\begin{tabular}{lccccc}
\hline & \multicolumn{4}{c}{ Stimulus Pair Magnitude } \\
\cline { 2 - 3 } $\begin{array}{l}\text { Question } \\
\text { Type }\end{array}$ & \multicolumn{2}{c}{ Comparative First } & & \multicolumn{2}{c}{ Comparative Last } \\
\cline { 2 - 3 } \cline { 5 - 6 } & Low & High & & Low & High \\
\hline Greater & $1449(.07)$ & $1528(.09)$ & & $1280(.07)$ & $1304(.08)$ \\
Lesser & $1412(.07)$ & $1633(.11)$ & $1248(.08)$ & $1417(.10)$ \\
Difference & 37 & -105 & & 32 & -113 \\
\hline
\end{tabular}

the usual form. Low-magnitude pairs were discriminated $32 \mathrm{msec}$ more rapidly, under the instruction to select the object of lesser magnitude. High-magnitude pairs were discriminated $113 \mathrm{msec}$ more rapidly, under the instruction to select the object of greater magnitude. As Table 5 indicates, these results were essentially unchanged in the comparative first condition: the corresponding differences were $37 \mathrm{msec}$ for low-magnitude pairs and $105 \mathrm{msec}$ for high-magnitude pairs. The magnitude of the congruity effect in the comparative first condition was $36 \mathrm{msec}$ (to the nearest millisecond), identical to that obtained in the comparative last condition.

Needless to say, the congruity effect was reliable in both the comparative last condition $[F(1,24)=17.26, M S e=$ $15,432, p<.01]$ and the comparative first condition $[F(1,21)=11.97, M S \mathrm{e}=18,474, p<.01]$. Analyzing both conditions together, there was a highly reliable effect of congruity $[F(1,45)=28.75, M S \mathrm{e}=16,852$, $p<.01]$. Of course, congruity did not interact with order $[F(1,45)<1, M S e=16,852]$.

\section{DISCUSSION}

From these results, it is clear that the congruity effect is robust with respect to the ordering of the comparative and the stimulus pair. For both salient and nonsalient pairs, there was no diminution in the magnitude of the effect when the comparative followed, rather than preceded, the stimulus pair. Thus, our findings, coupled with the original data provided by Holyoak and Mah (1981), indicate that the expectancy explanation of the congruity effect is incorrect.

It is not completely clear why Marschark (1983) obtained results so disparate from those reported here. Although he subsequently noted (Marschark, 1984) that the stimuli in his nonsalient condition were not as extreme as the pairs in the salient condition, it is remarkable that he obtained no congruity effect at all for the nonsalient stimuli. We might expect the confounding to diminish the congruity effect, but we find it surprising that it eliminated the effect entirely.

One possibility is that the experimental context, in Marschark's study, might have contributed to the reduction in magnitude of the congruity effect. Cech and Shoben (1985b) demonstrated that the congruity effect can be markedly affected by the experimental context. They asked subjects to determine the larger (or smaller) of pairs 
of objects in a variety of contexts. For example, let us consider the pair crocodile-lion. In the absence of explicit context, and from an examination of our norms (Shoben, Cech, \& Schwanenflugel, 1985), we would consider this pair moderately large. When these two items were the two largest (of six) in the study, RT to the instruction larger was much faster than RT to the instruction smaller. However, when this pair was in a context that included horse, rhino, and elephant, instruction had little, if any, effect on RT.

With Marschark's (1983) stimuli, the nonsalient items, in the context of many other pairs that are extreme in magnitude, may behave like the crocodile-lion example given above. In the presence of very extreme pairs, moderately extreme pairs may show little effect of instruction. Consequently, it appears that the magnitude of the congruity effect interacted strongly with salience. Although this explanation is admittedly speculative, context can have a powerful effect on the magnitude of the congruity effect for particular items, even when item pairs are never repeated (Čech \& Shoben, 1985a).

In contrast to Marschark's (1983) results, we found that the influence of the salience factor was very small. Although statistically significant in the overall analysis, the magnitude of the effect was only $22 \mathrm{msec}$. For our purposes, the important point is that it did not interact with the congruity effect. However, there is now a question as to what status salience should occupy. One speculation is that this factor reflects some relative ease of retrieval. It may be that this information is better known and, for whatever underlying theoretical reason, is also more readily retrieved. This speculation also accounts for why the salience effect is more pronounced when the comparative precedes the stimulus pair. In the comparative first condition, there is little time for subjects to activate their knowledge base, and, consequently, differences in retrieval may be more pronounced here than when the comparative follows the stimulus pair.

However, we should be cautious before accepting such an interpretation. Although we matched the salient and nonsalient stimuli as carefully as we could, the salient stimuli were slightly more extreme in magnitude (on average) than the nonsalient stimuli. Thus, our small effect simply may reflect our inability to precisely match these two pairs. Because extreme pairs are often discriminated more readily than are pairs of moderate magnitude, our salience effect may be only a reflection of this variable (Banks, 1977; Moyer \& Dumais, 1978; Shoben, Cech, Schwanenflugel, \& Sailor, in press ). Moreover, although the effect of salience was more pronounced when the comparative preceded the stimulus pair, the interaction of order with the salience value was not significant. Thus, it seems premature to ascribe any role to salience in comparative judgments.

\section{Accounts of the Congruity Effect}

Propositional accounts of comparative judgment (Banks, 1977) have long pointed to the congruity effect as a finding that is readily explicable by propositional accounts and is very difficult for analogical theories. According to the propositional accounts, the magnitudes of the objects are coded linguistically (e.g., fierce or small), and when these codes match the form of the question, decisions are easier than when the form of the question mismatches the coded magnitude of the objects. Thus, this account predicts congruity effects whether the comparative precedes or follows the stimulus pair.

The expectancy hypothesis (Marschark \& Paivio, 1981) allows analogical models to account for the congruity effect without recourse to assumptions about discrete codes. However, it appears that this account is inconsistent with the present results and with earlier findings that show no change in the magnitude of the congruity effect as a function of the order of the comparative and the stimuli (Banks et al., 1983).

Perhaps the most promising analogical account of the congruity effect is the reference point model proposed by Holyoak (1978; Holyoak \& Mah, 1982). According to this model, subjects compare the magnitudes of the two objects to a reference point and select the one that is closer to it. The congruity effect arises from the fact that there are two reference points, one for each of the poles of the dimension. RT is assumed to be an increasing function of distance from the reference point, and, accordingly, pairs are discriminated more readily when the form of the question selects the more proximate reference point. Because these processes do not change when the comparative is placed after the stimulus pair, the reference point model predicts congruity effects in both conditions.

Although the reference point model provides a satisfactory account of the congruity effects we observed, it, like the propositional model, has its detractors. Shoben, Cech, and Schwanenflugel (1983) claimed that the model provides little explanatory power and that the model has been applied to relatively limited domains. Moreover, Shoben et al. claimed that better accounts of those data are available.

Thus, our data have not enabled us to determine the correct account of the congruity effect in comparative judgments. However, coupled with the earlier results of Holyoak and Mah (1981), they do demonstrate that the expectancy hypothesis is no longer a viable account. This conclusion is important because this hypothesis has been the best explanation provided by analogical theorists. Without some new explanation, it appears that propositional accounts provide a superior account of the congruity effect in comparative judgments.

\section{REFERENCES}

BANks, W. P. (1977). Encoding and processing of symbolic information in comparative judgments. In G. H. Bower (Ed.), The psychology of learning and motivation (Vol. 11, pp. 101-159). New York: Academic Press.

Banks, W. P., White, H., Sturgill, W., \& Mermelstein, R. (1983). Semantic congruity and expectancy in symbolic judgments. Journal of Experimental Psychology: Human Perception \& Performance, 9. $560-582$

С̆ЕС, C. G., \& ShOBEn, E. J. (1985a). Choosing sizes: Coding processes in magnitude comparisons. Unpublished manuscript. 
С̆ech, C. G., \& Shoben, E. J. (1985b). Context effects in symbolic magnitude comparisons. Joumal of Experimental Psychology: Leaming. Memory, \& Cognition, 11, 299-315.

HoLYosk, K. (1978). Comparative judgments with numerical reference points. Cognitive Psychology, 10, 203-243.

HolyoAk, K., MAH, W. A. (1981). Semantic congruity in symbolic comparisons: Evidence against an expectancy hypothesis. Memory \& Cognition, 9, 197-204.

Holyoak, K., MAH, W. A. (1982). Cognitive reference points in judgments of symbolic magnitude. Cognitive Psychology, 14, 328-352.

MARSCHARK, M. (1983). Semantic congruity in symbolic comparisons: Salience, expectancy, and associative priming. Memory \& Cognition, 11, 192-199.

Marschark, M. (1984). Erratum. Memory \& Cognition, 12, 642.

Marschark, M., \& Paivio, A. (1979). Semantic congruity and lexical marking in symbolic comparisons: An expectancy hypothesis. Memory \& Cognition, 7, 175-184.

Marschare, M., \& Paivio, A. (1981). Congruity and the perceptual comparison task. Journal of Experimental Psychology: Human Perception \& Performance, 7, 290-308.

Moyer, R., \& LANDAUer, T. (1973). Determinants of reaction time for digit inequality judgments. Bulletin of the Psychonomic Society, 1, 167-168.

Moyer, R. S., Dumais, S. T. (1978). Mental comparison. In G. H. Bower (Ed.), The psychology of learning and motivation (Vol. 12, pp. 117-155). New York: Academic Press.

PaIvio, A. (1978). Mental comparisons involving abstract attributes. Memory \& Cognition, 6, 199-208.

Shoben, E. J., Cech, C. G., \& Schwanenflugel, P. J. (1983). The role of subtractions and comparisons in comparative judgments in- volving numerical reference points. Journal of Experimental Psychology: Human Perception \& Performance, 9, 226-241.

Shoben, E. J., Čeh, C. G., Schwanenflugel, P. J., \& Sallor, K. M. (in press). Serial position effects in comparative judgments. Joumal of Experimental Psychology: Human Perception \& Performance.

\section{NOTES}

1. Marschark (1984) noted this point himself after the publication of his original paper (Marschark, 1983).

2. Because of the different reliability, we might expect differences in ferocity to be greater than differences in size. People appear to know more about size and, consequently, can make finer discriminations. It is important that the difference in scaled magnitude not vary as a function of salience.

3. We followed the recommendations of Marschark (1983) in computing the magnitude of the congruity effect. That is, we subtracted the sum of the two congruent RTs from the sum of the two incongruent RTs and divided by four. Although one might be tempted to agree with Holyoak and Mah (1981) that two is a more appropriate divisor, we used Marschark's formulation both to maximize comparability between his experiment and ours and because the result obtained by dividing by four equals the average amount by which each point would have to be changed to remove the interaction completely (Banks et al., 1983).

(Manuscript received September 30, 1987; revision accepted for publication February 19, 1988.) 